\title{
Habilidades Sociais na Escola: Relato de Experiência de Estágio em Psicologia Escolar
}

\author{
Habilidades Sociales en la Escuela: Relato de Experiencia de Práctica en Psicología Escolar
} Social Skills at School: Report of Internship Experience in School Psychology

Jéssica Reusch Cruz

ORCID: https://orcid.org/0000-0003-1757-0539 Faculdade Meridional, Rio Grande do Sul/Brasil

Márcia Fortes Wagner

ORCID: https://orcid.org/0000-0003-0457-3773 Faculdade Meridional, Rio Grande do Sul/Brasil

Naiana Dapieve Patias

ORCID: https://orcid.org/0000-0001-9285-9602

Declaração de Direito Autoral

A submissão de originais para este periódico implica na transferência, pelos autores, dos direitos de publicação impressa e digital. Os direitos autorais para os artigos publicados são do autor, com direitos do periódico sobre a primeira publicação. Os autores somente poderão utilizar os mesmos resultados em outras publicações indicando claramente este periódico como o meio da publicação original. Em virtude de sermos um periódico de acesso aberto, permite-se o uso gratuito dos artigos em aplicações educacionais e científicas desde que citada a fonte conforme a licença CC-BY da Creative Commons.

\section{Resumo}

Habilidades sociais (HS) podem ser compreendidas como classes de comportamentos no repertório do indivíduo para lidar de maneira adequada com as situações interpessoais, sendo um construto teórico vinculado ao modelo comportamental. Este estudo tem por objetivo relatar a experiência de um estágio curricular em Psicologia que teve foco no desenvolvimento de habilidades sociais em 32 estudantes, sendo 12 alunos de Ensino Médio e 20 de Educação de Jovens e Adultos (EJA). O intuito dos grupos foi promover habilidades comunicacionais mais eficazes e prevenir conflitos. Foram realizados seis encontros, um por semana com cada turma, no turno da noite, com a duração média de 45 minutos cada encontro. As intervenções foram por meio de diálogos, utilização de recursos audiovisuais, dinâmicas e dramatizações. A partir das intervenções propostas, buscou-se possibilitar o desenvolvimento de comportamentos mais assertivos dos alunos em sala de aula, por meio da expressão de seus pensamentos e sentimentos de forma clara, preservando os direitos dos outros e sem prejudicar aos seus próprios direitos, a fim de diminuir os conflitos e melhorar as relações interpessoais. Os resultados apontaram para a melhoria das relações interpessoais no ambiente escolar, conforme observação do comportamento e relato dos próprios alunos e professores.

Palavras-chaves: Psicologia escolar; Relações interpessoais; Habilidades sociais.

\section{Resumen}

Habilidades sociales (SA) pueden ser entendidas como comportamientos individuales en el repertorio de clase para tratar adecuadamente las situaciones interpersonales, una construcción teórica que se vincula con el modelo de comportamiento. Este estudio tiene por objeto informar de la experiencia de un período de prácticas en psicología que se había centrado en el desarrollo de habilidades sociales en 
32 estudiantes, 12 estudiantes de la escuela secundaria y 20 jóvenes y Educación de Adultos (EJA). El objetivo del grupo era promover las habilidades de comunicación más eficaces y prevenir conflictos. Se realizaron seis reuniones, una por semana con cada clase, durante el turno de la noche, con una duración promedio de 45 minutos por reunión. Las intervenciones fueron a través de diálogos, uso de recursos audiovisuales, dinámicas y dramatizaciones. Sobre la base de las intervenciones propuestas, fue posible desarrollar comportamientos más asertivos de los estudiantes en el aula, expresando sus pensamientos y sentimientos de manera clara, preservando los derechos de los demás y sin perjuicio de sus propios derechos, con el fin de reducir los conflictos y mejorar las relaciones interpersonales. Los resultados apuntaron a la mejora de las relaciones interpersonales en el entorno escolar, de acuerdo con la observación del comportamiento y el informe de los propios alumnos y profesores.

Palabras clave: Psicología escolar; Relaciones interpersonales; Habilidades sociales.

\begin{abstract}
Social skills (HS) can be understood as classes of behaviors in the repertoire of the individual to deal adequately with interpersonal situations, being a theoretical construct linked to the behavioral model.This study aims to report the experience of a traineeship in psychology that had focused on developing social skills in 32 students, 12 students from high school and 20 Youth and Adult Education (EJA). Six meetings were held, one week with each class, the night shift, with the average duration of 45 minutes each meeting. The interventions were through dialogues, use of audiovisual resources, dynamics and dramatizations. From the proposed interventions, aimed to enable the development of more assertive behaviors of students in the classroom, by expressing their thoughts and feelings in a clear way, preserving the rights of others and without prejudice to their own rights, to reduce conflicts and improve interpersonal relationships. The results pointed to the improvement of the interpersonal relations in the school environment, according to observation of the behavior and report of the students and teachers themselves.
\end{abstract}

Keywords: School Psychology; Interpersonal relationships; Social skills.

\section{Introdução}

Habilidades sociais (HS), de acordo com a definição clássica da literatura (Caballo, 1996), podem ser compreendidas como comportamentos de um indivíduo manifestados em determinadas situações, os quais buscam respeitar aos demais, resolver os problemas imediatos e minimizar a sua ocorrência no futuro. Referem-se à "existência de diferentes classes de comportamentos sociais no repertório do indivíduo para lidar de maneira adequada com as demandas das situações interpessoais" (Del Prette \& Del Prette, 2001, p. 31).

Levando-se em consideração seus distintos conteúdos e funções, as HS podem ser subdivididas em diferentes classes. Entre elas, destacam-se: HS de comunicação (fazer e responder perguntas, pedir a opinião avaliativa, conseguir iniciar e manter uma conversar, dar e receber elogios); de civilidade (dizer por favor, agradecer, fazer a sua apresentação e cumprimentar as pessoas); de empatia (refletir sentimentos e expressar apoio); de assertividade (expressar a sua opinião, concordando e discordando dos demais, fazer, aceitar e recusar pedidos, conseguir pedir desculpas e admitir que falhou, estabelecer relacionamentos afetivos, expressar raiva e pedir mudança de conduta); de trabalho (coordenação de grupos, falar em público, conseguir solucionar problemas, tomar decisões , mediando conflitos e habilidades educativas); e de expressividade emocional (fazer amizades expressar solidariedade e cultivar o amor), levando-se em consideração seus distintos conteúdos e funções (Del Prette \& Del Prette, 2001).

No contexto escolar, as interações sociais nem sempre ocorrem de maneira 
saudável e acabam interferindo na aprendizagem escolar. Nesse sentido, uma das possibilidades de atuação durante o estágio de psicologia na escola pode ser o trabalho com grupos de alunos, pais e/ou professores, com o intuito de diminuir ou auxiliar na resolução de diversos conflitos (Andrada, 2005; Dias, Patias, \& Abaid, 2014; Santos, Menezes, Borba, Ramos, \& Costa, 2017). Exemplo disso são os grupos de treinamento e/ou desenvolvimento de HS, os quais podem promover proteção a comportamentos de riscos e favorecer $o$ relacionamento saudável entre os alunos. $\mathrm{O}$ treinamento das HS tem por objetivo fornecer oportunidades e ferramentas para que os alunos possam compreender sobre as suas potencialidades e responsabilidades na administração da convivência com seus pares (Maia \& Lobo, 2013).

Tais habilidades são aprendidas e aperfeiçoadas ao longo da vida, manifestandose por meio de interações sociais cotidianas. As práticas educativas da família e da escola promovem condições para a obtenção e aprimoramento das HS e da competência social, refletindo na qualidade de vida das pessoas (Del Prette \& Del Prette, 2011). É possível afirmar que as HS podem ser situacionais/culturais, aprendidas e ensinadas, o que as aproxima do construto teórico da Terapia Comportamental (Del Prette \& Del Prette, 2019).

Embora os conceitos de HS e de competência social tenham similaridades, é fundamental diferenciá-los. Enquanto as HS são determinadas em termos descritivos, levando-se em consideração as classes do desempenho que ocorrem na interação das pessoas, a competência social pode ser compreendida como um construto avaliativo desse desempenho (Del Prette \& Del Prette, 1999, 2005). Dessa forma, um bom repertório de HS pode ser necessário, mas não é o suficiente para se atingir a competência social (Del Prette \& Del Prette, 2019) e uma pessoa, para ser socialmente competente, deve buscar atingir seus objetivos de uma maneira assertiva, mantendo equilíbrio entre seus interesses pessoais e os dos demais nas relações interpessoais (Del Prette \& Del Prette, 2005 2009a). Assertividade é um conceito crucial para se distinguir HS de competência social, podendo ser descrita como a habilidade do indivíduo em demonstrar seus pensamentos e sentimentos, preservando os direitos dos outros e sem prejudicar aos seus próprios direitos (Del Prette \& Del Prette, 1999). Uma postura assertiva está embasada na "noção de igualdade de direito e deveres, de legitimidade dos comportamentos voltados para a reivindicação e defesa desses direitos, de respeito e dignidade da pessoa humana" (Del Prette \& Del Prette, 2005, p.175).

No campo das HS, há avanços no desenvolvimento de procedimentos e estratégias que permitiram constituir a intervenção denominada Treinamento em Habilidades Sociais (THS). Esse programa é

um conjunto de atividades planejadas que estruturam processos de aprendizagem, mediados e conduzidos por um terapeuta ou coordenador, visando a: (a) ampliar a frequência e/ou melhorar a proficiência de HS já aprendidas, mas deficitárias; (b) ensinar novas HS significativas; (c) diminuir ou extinguir comportamentos concorrentes com tais habilidades. (Del Prette \& Del Prette, 2010, p. 128).

Uma proposta de treinamento das HS está relacionada a uma classe de respostas aprendidas, possibilitando que o indivíduo consiga estabelecer a ação e a condução da interação social de modo adequado (Del Prette \& Del Prette, 2013). O THS pode ser compreendido como um enfoque terapêutico que visa desenvolver formas de enfrentamento perante situações difíceis da vida e caracterizase por ser uma forma direta e sistemática de incrementar o repertório de HS aos indivíduos, com a intenção de melhorar sua competência em situações sociais específicas (Caballo, 2012). Para atingir os objetivos da intervenção, pode ser utilizado o método vivencial, que apresenta "um caráter interativo, que favorece um ambiente de relações de apoio mútuo" (Del 
Prette \& Del Prette, 2010, p. 107). As vivências, nesse sentido, são situações nas quais ocorra a interação social entre os participantes, as quais podem mobilizar sentimentos, pensamentos e ações dos indivíduos, a fim de atingir o repertório deficitário e desenvolver as habilidades sociais.

A aplicação do THS em distintos grupos

busca verificar sua eficácia no desenvolvimento das HS, incrementando a capacidade de interação e qualificando a competência social (Del Prette \& Del Prette, 2013). Uma investigação conduzida em um grupo de 10 adolescentes de comunidades do Rio de Janeiro, com idade entre 13 a 17 anos, visou avaliar os efeitos de um programa de HS no repertório de habilidades sociais, autoeficácia e percepção de apoio social realizado (Leme, Fernandes, Jovarini, Achkar, \& Del Prette, 2016), conduzido em 10 encontros. Os participantes responderam, antes e após a intervenção, ao Inventário de Habilidades Sociais para Adolescentes (Del Prette \& Del Prette, 2009), à Escala de Autoeficácia (Leme, Coimbra, Gato, Fontaine, \& Del Prette, 2013) e à Escala de Percepção de Apoio Social (Squassoni \& Matsukura, 2014). Os resultados indicaram aumento nos níveis de habilidades sociais, apoio social dos professores e autoeficácia.

Da mesma maneira, a literatura vem destacando algumas intervenções de THS com população universitária. Uma proposta de THS grupal com uma amostra de 22 acadêmicos com sintomas de ansiedade social, provenientes de diversos cursos de uma universidade privada, foi conduzida ao longo de 10 sessões, com periodicidade semanal. Os instrumentos utilizados foram: Questionário de Ansiedade Social para Adultos/CASO (Caballo, Salazar, Irurtia, Arias, \& Hofmann, 2010a; Caballo, Salazar, Arias, Irurtia, \& Calderero, 2010b; Wagner, Moraes, Oliveira, \& Oliveira, 2017), Escala de Ansiedade Social Liebowitz (Terra et al, 2006), Inventários de Depressão (BDI) e de Ansiedade (e BAI) de Beck (Cunha, 2001). A comparação dos resultados pré e pós intervenção apontou que os participantes tiveram uma melhora significativa nos sintomas de ansiedade social (Pureza, Rusch, Wagner, \& Oliveira, 2012).

Outro programa de intervenção de HS foi descrito com 32 estudantes do curso de Psicologia, em 10 sessões, no qual foram abordados temas como manejo da ansiedade, assertividade, técnicas de relaxamento, relações interpessoais, falar em público e expressão de sentimentos (Wagner, Pereira, \& Oliveira, 2014). Os resultados mostraram que mudanças significativas foram produzidas nas medidas pós-tratamento, em comparação com as medidas pré-tratamento, nos escores globais e nas cinco dimensões do CASO (Caballo et al., 2010a, 2010b; Wagner et al., 2017). Os achados permitiram afirmar que o programa de THS foi eficaz para diminuir a ansiedade social dos universitários, mostrando diferenças na média grupal após a intervenção, tanto do escore total, quanto dos 5 fatores do instrumento, em comparação com os resultados obtidos no início do programa.

Investigações conduzidas em outros países também reforçam que intervenções voltadas ao desenvolvimento de HS trazem benefícios aos participantes. Um estudo espanhol foi aplicado em 1040 estudantes universitários entre 18 e 44 anos, com o objetivo de analisar as características psicométricas do instrumento Cuestionario Honey Alonso de Estilos de Aprendizaje (CHAEA) (Alonso, Gallego, \& Honey, 1994) e analisar os efeitos do trabalho cooperativo em equipe com técnicas de aprendizagem e habilidades sociais. Nos resultados foram obtidos três fatores de "Habilidades de autoafirmação", "Habilidades de recepção de informação" e "Habilidades de emissão de informação", concluindo-se que o trabalho cooperativo com técnicas de aprendizagem influi nas habilidades sociais da equipe (Del Barco, Castaño, Lázaro, \& Gallego, 2015).

Um estudo caracterizou um grupo de universitários de Informática e Psicologia, com idades entre 16 e 49 anos, quanto ao repertório de HS e os resultados indicaram percepção moderada da vivência acadêmica e do repertório de habilidades sociais, bem como 
correlações de baixa magnitude entre as variáveis sexo e curso (Soares, Mourão, Santos, \& Mello, 2016). Outro estudo recente com aplicação do THS e da Avaliação de um programa de Desenvolvimento Interpessoal profissional para universitários de Ciências Exatas foi desenvolvido por Lopes, Dascanio, Ferreira, Del Prette \& Del Prette (2017). Participaram 35 estudantes, 23 homens e 12 mulheres, distribuídos em três diferentes grupos consecutivos de intervenção. A avaliação do repertório de habilidades sociais foi realizada com o IHS-Del Prette (Del Prette, \& Del Prette, 2016), antes, em uma sessão intermediária, imediatamente após o programa e três meses ao término da intervenção. Tanto nos resultados de grupo como nos individuais, os autores constataram aquisições em habilidades sociais e sua manutenção, especialmente no escore total e nas subescalas F1 - Enfrentamento com risco e F4 Autoexposição a desconhecidos. Os achados apontam que a valorização das relações interpessoais no trabalho tem propiciado novas demandas para a formação profissional universitária, especificamente, em relação ao ensino e desenvolvimento de habilidades interpessoais associadas às habilidades acadêmicas e técnicas. Assim, os resultados indicaram a eficácia e efetividade do programa de desenvolvimento profissional interpessoal para universitários.

O objetivo deste estudo é relatar a experiência de um estágio curricular em Psicologia que teve foco no desenvolvimento de habilidades sociais em estudantes de Ensino Médio e de Educação de Jovens e Adultos (EJA), com o intuito de promover comportamentos mais assertivos, por meio da expressão de seus pensamentos e sentimentos de forma clara, preservando os direitos dos outros e sem prejudicar aos seus próprios direitos, a fim de diminuir os conflitos e melhorar as relações interpessoais. A apresentação do presente relato de experiência seguiu as características principais que foram

\footnotetext{
${ }^{1}$ Em alguns encontros, tanto do grupo do Ensino Médio como da Educação de Jovens e Adultos (EJA), nem todos os alunos estavam presentes, pois faltavam as
}

sistematizadas por Tosta, Silva e ScorsoliniComin (2016). As mesmas referem-se à estrutura do manuscrito de relato de experiência, os aspectos éticos, a reflexão e criticidade, os aspectos metodológicos, as evidências para a prática, sua relevância científica e seus resultados e implicações.

\section{Método}

$\mathrm{O}$ estágio curricular foi realizado em dois semestres letivos (aproximadamente 8 meses). $\mathrm{O}$ mesmo foi supervisionado, semanalmente, na faculdade na qual foi realizado. Seu objetivo inicial foi a observação do contexto em que o mesmo era realizado com a finalidade de verificar demandas para, posteriormente, intervir. A escola em que foi realizado o estágio é pública estadual, situada em uma cidade da região do norte do Estado do Rio Grande do Sul. A mesma atende Ensino Fundamental anos iniciais e finais, Ensino Médio e Educação de Jovens e Adultos (EJA). As intervenções efetivadas foram a observação do contexto escolar, escutas individuais de professores, pais e alunos, além de trabalhos em grupos com professores e alunos, com a realização de anotações em um diário de campo, pela estagiária.

Neste estudo descreve-se, de forma breve, a atividade em grupo realizada com um total de 32 alunos, divididos em dois grupos: 12 alunos do Ensino Médio e 20 alunos da EJA. ${ }^{1}$ O mesmo foi elaborado com o objetivo de desenvolvimento e treinamento de HS, considerando as especificidades do contexto escolar e dos alunos das turmas envolvidas. As atividades ocorreram no turno da noite, no qual os alunos encontravam-se matriculados, em espaço e momento cedidos pela escola e professores, com a duração média de 45 minutos cada encontro. Foram realizados seis encontros com cada turma, um por semana, totalizando um mês e meio de intervenção. Os mesmos ocorreram por meio de diálogos, com auxílio de recursos audiovisuais (vídeos e

aulas. Desta forma, o número máximo de alunos por grupo foi de 12 no Ensino Médio e de 20 na Educação de Jovens e Adultos. 
slides), dinâmicas e dramatizações, proporcionando aos grupos o desenvolvimento das suas habilidades sociais e a prevenção de conflitos, por meio da aprendizagem de estilos de comunicação mais eficazes.

Como esse manuscrito trata-se de um relato de experiência, foi pedido autorização para a publicação, de forma retrospectiva, sendo solicitada a assinatura do Termo de Consentimento Livre e Esclarecido (TCLE) à escola e aos participantes. No TCLE, informouse o objetivo do estudo e a garantia do sigilo e confidencialidade dos dados, bem como das informações pessoais.

\section{Resultados A demanda}

A estagiária de psicologia, após alguns meses de observação e escutas individuais e em grupo, percebeu a necessidade de trabalho em habilidades sociais, devido aos conflitos interpessoais existentes por falhas na comunicação entre alunos e entre alunos e professores. Além disso, a partir de observações das turmas de Ensino Médio e de EJA, foi constatada a dificuldade de alguns alunos em se expressar de forma assertiva. Sendo assim, ao discutir com alunos e professores, foi construído um projeto com o objetivo de trabalhar habilidades sociais com os alunos. Após concordância dos alunos e da escola, foram combinados dias e horários para os encontros. O objetivo era construir um grupo que pudesse propiciar aos alunos o conhecimento e a vivência de formas mais assertivas de expressão e comunicação. Embora as atividades propostas tenham sido construídas a partir de leituras prévias sobre autores clássicos e atuais referentes às HS e ao THS, a atividade desenvolvida e descrita foi adaptada, considerando-se o contexto escolar, condições físicas e de tempo, além dos imprevistos ocorridos, como greves e atestados de professores.

\section{Os encontros}

Primeiro Encontro: $O$ contrato e o "quebra gelo"
No primeiro encontro foi realizado o contrato, ou seja, a explanação dos objetivos do projeto, as expectativas, o tempo de duração, os dias e os horários, assim como a execução de um contrato escrito. Com a turma da Educação de Jovens e Adultos (EJA) ocorreu a apresentação dos participantes por meio de uma dinâmica de "quebra gelo" chamada de "Jogo do novelo ou do barbante" a qual consiste em fazer uma roda e todos participantes ficarem em pé. Joga-se o novelo para um participante que dá início, enrolando o novelo no dedo e jogando para o outro, após dizer o seu nome e formular uma pergunta sobre algo que não saiba a respeito do colega, como por exemplo, "quais são suas músicas favoritas". Logo após o colega responder, também diz o seu nome, enrolando o novelo no dedo e jogando para outra pessoa. Assim foi feito sucessivamente, até que todos do grupo tivessem se apresentado. Como cada um atirou o novelo adiante e, ao final, no interior do círculo se formou uma teia de fios que uniu uns aos outros, simbolizando a criação da integração do grupo. Neste momento, a estagiária conversou sobre a importância do respeito no grupo, para que os encontros possam ocorrer da maneira planejada.

O fechamento do primeiro encontro foi realizado com uma dinâmica de reflexão, referente às expectativas dos alunos, na qual deveriam escrever uma carta para si próprio. Essa carta deveria conter as expectativas, sentimentos e planejamentos futuros, sendo entregue à estagiária, que se responsabiliza por devolver no último encontro aos participantes.

Com a turma do ensino médio, foi realizado o contrato e apresentação do projeto. Além disso, houve o fechamento do primeiro encontro com a dramatização de uma situação rotineira que os alunos trouxeram para exemplificar as habilidades sociais relacionadas ao contexto escolar, como por exemplo, os atrasos, chegar atrasado na escola, chegar atrasado em uma entrevista de emprego. Neste dia, foi deixada uma caixa na sala de aula até o período posterior no qual os alunos poderiam colocar assuntos que lhe 
interessavam e que poderiam ser trabalhos pensando nas habilidades sociais.

Nos dois grupos (EJA e ensino médio), os alunos mostraram-se participativos, atentos e interessados nas propostas. O grupo do ensino médio foi bastante questionador quanto à temática do projeto, e o grupo do EJA mostrouse disponível e ansioso para saber mais sobre a temática.

\section{Segundo Encontro: Conceituando Habilidades Sociais e estilos de comportamento}

No segundo encontro com a turma da EJA, foi esclarecido o conceito de habilidades sociais e explicitada a temática, relacionando a importância do seu desenvolvimento, o seu objetivo e refletindo acerca do valor dos aspectos que envolvem $\mathrm{o}$ processo das habilidades. Houve a apresentação à turma dos três estilos de resposta de comportamento, o qual contempla o comportamento não assertivo (passivo), agressivo e o assertivo. Foi entregue uma folha com o resumo dos estilos. Explicouse que, no estilo não assertivo (passivo), os comportamentos não verbais geralmente relacionam-se com olhos que fitam para baixo, voz baixa, vacilações, gestos desvalidos, postura abatida, evitação das situações, retorcer as mãos, tom vacilante ou de queixa, risadinhas "falsas". Já os comportamentos verbais possuem relação com as expressões "Talvez", "suponho", "me pergunto se poderíamos", "se importaria muito", "somente", "não crê que", "eh", "bom", "realmente não é importante", "não se incomode". Os efeitos deste estilo incluem conflitos interpessoais; depressão; desamparo; imagem pobre de si mesmo; maltratar-se; perder oportunidades; tensão; sentir-se sem controle; solidão; não gostar de si mesmo, nem dos demais; sentir-se entediado e com mal-estar (Caballo, 2007).

Após, explicou-se o estilo agressivo, que geralmente inclui os comportamentos não verbais de olhar fixo, voz alta, fala fluente e rápida, enfrentamento, gestos de ameaça, postura intimidativa, desonesto/a, mensagens impessoais. Os comportamentos verbais incluem: "faria melhor heim", "faz", "tenha cuidado", "deve estar brincando", "não sabe?", "se você não fizer ...", "deveria", "mal". Os efeitos deste estilo relacionam-se com conflitos interpessoais, culpa, frustração, imagem pobre de si mesmo, prejudicar os demais, perder oportunidades, tensão, sentir-se sem controle, solidão, não gostar dos demais, sentir-se entediado e com mal-estar. Por fim, foi explicado o estilo assertivo, no qual os comportamentos não verbais incluem contato visual direto, nível de voz natural em conversa, fala fluente, gestos firmes, postura ereta, mensagens na primeira pessoa, ser honesto/a, verbalizações positivas, respostas diretas à situação, mãos soltas. Já os verbais seriam "penso", "sinto", "faço", "quero", "o que você pensa?" "o que você acha sobre isto?", "como podemos resolver isso?". Os efeitos deste estilo são positivos como, por exemplo, a resolução de problemas, sentir-se satisfeito, sentir-se à vontade com os demais e consigo mesmo, sentir-se relaxado. Além disso, pessoas que possuem o estilo assertivo tendem a ter controle, acreditar, criar e promover a maioria das oportunidades. $\mathrm{O}$ fechamento do encontro fez-se efetuando um resumo das atividades ponderadas no período, com espaço para esclarecimentos, dúvidas, opiniões (Caballo, 2007).

Já com o segundo ano do Ensino Médio, sucedeu-se a retomada do contrato com o grupo e também a explicação sobre o projeto, pois havia alunos que não tinham comparecido no primeiro encontro. Após, houve a dinâmica da "carta para si próprio", como ocorreu no primeiro encontro com o grupo da EJA. A finalização do encontro transcorreu por meio das sugestões de assuntos feito pelos alunos e sobre situações cotidianas em que possuíam dúvidas/ interesses. Ao final, foi apresentado à turma os três estilos de resposta, com a entrega do material "Contemplando o comportamento não assertivo (passivo), agressivo e o assertivo" (Del Prette \& Del Prette, 2009b).

\section{Terceiro Encontro: Reforçando conceitos $e$ dramatizando situações cotidianas}


O encontro realizado com a turma da EJA foi para reforçar os conceitos abordados na semana anterior, clarificando algumas dúvidas e abordando questões envolvidas no cotidiano dos alunos. Foi realizada a dinâmica "tiro pela culatra" na qual cada um escolhe uma tarefa/atividade/mico para que o colega da sua esquerda faça. No momento em que todos estavam escolhidos, a instrução foi para que os próprios alunos que escreveram a tarefa a executassem. Esta dinâmica teve o intuito de refletir sobre o conceito de empatia, exemplificando os comportamentos assertivos que podem ser efetuados, os agressivos e os não assertivos (passivos). A finalização do encontro deu-se com a colocação de uma situação cotidiana dos alunos, que causava angústia. A mesma foi dramatizada na sala de aula, com a participação voluntária de dois alunos. No momento, houve troca de papéis e a pontuação dos três estilos de comportamento, segundo Caballo (2007).

No encontro com o grupo de alunos do ensino médio foi explicitado o modelo da área do desenvolvimento das habilidades sociais, segundo Caballo (1996), com a entrega do material dos três estilos de comportamento. Foi realizada a leitura dos comportamentos e exemplificado a diferença entre eles, desde os comportamentos não verbais para os verbais e sua utilização cotidiana. Como o grupo já havia selecionado algumas situações em que gostaria de trabalhar, foi ressaltado o assunto que abordava questões sobre a primeira entrevista, currículo e apresentação pessoal no trabalho. Neste momento, foi trabalhada a forma mais assertiva de se apresentar na empresa, como enviar o currículo, quais as informações adequadas para colocar, como colocar, como se preparar para ir ao dia da entrevista. Nessa perspectiva, os alunos questionaram, em relação ao comportamento mais adequado, como por exemplo: "O que preciso levar no dia da entrevista?" "Qual é o horário que precisa chegar?" "Colocar foto ou não, no currículo?" "Não tenho experiências, meu currículo é ruim?". O fechamento com o grupo foi pautado sobre a importância do desenvolvimento das habilidades sociais nesse contexto, do seu objetivo, incentivando os alunos acerca do valor desses comportamentos e as consequências da sua utilização (Deming, 2017).

\section{Quarto Encontro: Autoconhecimento, autocontrole e comportamentos cotidianos}

Nesse encontro, foi realizada uma troca de temática devido à necessidade manifestada nos encontros anteriores. $\mathrm{O}$ tema acrescentado foi de autoconhecimento e autocontrole. Foi proposta a dinâmica "reflexão sobre autoconsciência". Foi pedido que os alunos pensassem em, no mínimo, cinco características próprias positivas e cinco características negativas, relacionadas às habilidades sociais (aos três estilos de comportamento, retirado de Caballo, 2007).

A reflexão feita foi para clarificar sobre os comportamentos feitos no dia a dia, as próprias características, sobre a influência delas no cotidiano e sua utilização delas mesmo sem estarmos conscientes. Após relacionados os conceitos de autoconhecimento e autocontrole, houve o fechamento com uma música e com uma cópia da letra da mesma para cada um, concretizado e levado em consideração a singularidade dos sujeitos, a compreensão do conhecimento, as diferenças e o respeito, a empatia que precisa estar envolvida em nosso contexto.

Na turma do Ensino Médio, a reflexão foi realizada para clarear os comportamentos cotidianos que derivam de características próprias de cada um, muito parecida com a turma do EJA, havendo diferenças na maneira de receber o conteúdo trabalhado e elaborar, pois, a turma do ensino médio causou aparentemente um desconforto, agitação. O fechamento em ambas as turmas foi realizado com o intuito de priorizar a conscientização e responsabilização dos comportamentos feitos por cada um, sendo assim a atividade veio para esclarecer que, quanto mais tivermos autoconhecimento, mais podemos ter o controle dos nossos comportamentos e agirmos de uma maneira mais assertiva. 


\section{Quinto Encontro: Aplicação prática de conceitos abordados}

Neste encontro, foi feita a aplicação prática dos conceitos abordados anteriormente, retomando os principais pontos ponderados dos três estilos de comportamento, sendo realizada a dinâmica "escolhendo as palavras". Para a dinâmica, organizou-se o grupo e foram distribuídas frases agressivas/ofensivas, que causaram desconforto e que são comuns no cotidiano da escola. Os alunos que se sentiram à vontade para dramatizar as frases puderam fazê-las na sala, exemplificando cada frase. $\mathrm{Na}$ dramatização, era necessário aparecer os três estilos de resposta, mostrando a possibilidade das pessoas se comportarem das três formas, na mesma situação. A mesma teve como objetivo estimular/incentivar a aprendizagem das concepções sobre comportamento assertivo, não assertivo e agressivo (Caballo, 2007).

A dinâmica foi realizada com a dramatização em sala de aula e a participação da maioria dos alunos. Os mesmos retiravam da caixa algumas situações cotidianas e precisavam expor a forma como reagiriam e qual seria a forma mais adequada. $\mathrm{O}$ encontro foi dinâmico, bem humorado e reflexivo com ambas as turmas, pois existiam várias situações frequentes do dia a dia, como por exemplo: "Estamos na aula de literatura e tenho uma dúvida sobre o conteúdo, quero muito fazer, mas meus colegas podem rir de mim"; Situação: "Compra de um sapato em uma loja da avenida. Quando chego em casa para prová-lo novamente, percebo que o salto está com defeito".

O fechamento dos encontros foi realizado a partir da reflexão sobre como as habilidades sociais fazem diferença no bemestar dos sujeitos envolvidos. Ainda, conversou-se sobre a importância do treino e desenvolvimento de comportamentos mais assertivos que visam melhorar a qualidade nas relações, o respeito das interações sociais, juntamente com o autocontrole das emoções e pensamentos.

\section{Sexto e último encontro: Retomada dos conceitos, feedback e fechamento}

O último encontro com ambas as turmas foi destinado para esclarecimentos e dúvidas que ainda restavam sobre os assuntos abordados. Neste encontro, foi conversado e treinado o feedback, sendo uma possibilidade de modelagem do comportamento, uma técnica auxiliar no ensaio comportamental, por meio da verbalização (adaptado de Del Prette \& Del Prette, 2009a).

O encontro foi iniciado com a proposta da dinâmica "dentro e fora do coração", com o intuito de reforçar comportamentos assertivos efetuados por eles, e para a reflexão pessoal de como estão se relacionando e sendo percebidos pelo grupo. A dinâmica funcionou da seguinte forma: no primeiro momento, foram distribuídas folhas para todos os participantes. Os mesmos deveriam escrever dentro do coração aspectos positivos (comportamento assertivo) dos colegas e, fora do coração, aspectos negativos (comportamento agressivo e/ou passivo) dos colegas, expressando de uma forma objetiva e com respeito. Após a dinâmica, propôs-se a reflexão acerca da demanda, como por exemplo, como é difícil lidar com aspectos que são negativos, como os outros nos percebem e sobre a possibilidade de melhorar esses aspectos, utilizando o comportamento assertivo.

Houve também a devolutiva da primeira dinâmica feita, as "cartas para si próprio" que os alunos desenvolveram no início do grupo. Neste momento, todos leram as cartas, de forma individual e, de forma coletiva, pode-se refletir sobre o projeto, a aprendizagem, o desenvolvimento pessoal, sobre a percepção e a compreensão das habilidades sociais. Alguns alunos se sentiram à vontade para falar sobre as suas cartas, relatando a diferença sobre como pensavam antes a respeito das habilidades sociais e o que perceberam após o THS. O encerramento foi realizado em forma de feedback com os alunos das duas turmas, expondo questões como quais foram os pensamentos, sentimentos, comportamentos desenvolvidos até o atual momento. 


\section{Discussão}

O objetivo deste artigo foi relatar a experiência de um estágio curricular em Psicologia que teve foco no desenvolvimento de habilidades sociais em estudantes de uma escola estadual, ocorrida em estágio básico curricular. O intuito dos grupos foi desenvolver comportamentos mais assertivos, por meio da expressão de pensamentos e sentimentos de forma sincera, aprender a lidar com críticas e elogios, pedir desculpas e escutar empaticamente, a fim de diminuir conflitos e melhorar as relações interpessoais, buscando preservar os direitos dos outros e não prejudicar aos seus próprios direitos (Caballo, 2012; Del Prette, Falcone, \& Murta, 2013). Além dos conteúdos expressos pela fala, é igualmente relevante a comunicação não verbal como compreensão do ambiente. A escolha da abordagem veio ao encontro da literatura (Caballo, 2012; Maia \& Lobo, 2013; Del Prette $\&$ Del Prette, 2013, 2017), que considera o THS uma ferramenta que pode auxiliar os indivíduos a compreenderem as suas responsabilidades na convivência com seus pares, tornando as interações sociais mais adequadas e saudáveis.

Por questões econômicas, físicas e situacionais do contexto escolar geral e, principalmente, da instituição na qual foi realizado o estágio, a intervenção buscou inserir todos os alunos, para que tivessem a oportunidade de entender e aprender formas ou estratégias mais assertivas diante de situações cotidianas da escola e da vida pessoal. Desta forma, as propostas de intervenção foram planejadas de acordo com as demandas primordiais do contexto, simultaneamente voltadas à promoção de saúde dos indivíduos envolvidos, buscando resolver conflitos interpessoais por meio da utilização das habilidades sociais. Durante a aplicação do projeto, ocorreram algumas alterações no planejamento inicial, devido à demanda apresentada pelos sujeitos ou pelo próprio contexto. Por exemplo, em um dos encontros foi necessário acrescentar os conceitos de autoconsciência e autocontrole. Assim, tais modificações estimularam a maior compreensão dos alunos a respeito do uso assertivo do comportamento, a fim de colocarem em prática tais conceitos em sua rotina diária. Del Prette e Del Prette (2001, $2009 b$, 2019) reforçam o quanto o THS, planejado de acordo com as demandas dos sujeitos, pode auxiliar no desenvolvimento da assertividade, pois ser assertivo envolve elementos que considerem o respeito aos demais e a igualdade de direitos e deveres.

Segundo Del Prette, Paiva e Del Prette (2005), a qualidade das relações interpessoais que ocorrem na escola precisa ser visualizada com um enfoque mais amplo, visando alterações dos processos educativos e mudanças sociais. Nesse sentido, o grupo de desenvolvimento das habilidades sociais propiciou desafios, ao estimular a capacidade de articular aspectos de um contexto interativo em dimensões pessoais, situacionais e culturais. A utilização de métodos vivenciais segue as orientações de Caballo (2003) e Del Prette e Del Prette (2010), pesquisadores que afirmam que as vivências são uma forma de fortalecer as capacidades do indivíduo, de acordo com as metas da intervenção, mobilizando sentimentos, pensamentos e ações dos indivíduos, com o intuito de desenvolver as HS.

Ao longo da aplicação da intervenção, percebeu-se o envolvimento dos alunos que participaram efetivamente das atividades propostas por meio da discussão e do uso das habilidades em outros contextos como, por exemplo, no trabalho e no ambiente familiar. Ainda, os resultados das atividades desenvolvidas foram percebidos na melhoria das relações interpessoais no ambiente escolar, conforme observação do comportamento e relatos verbais dos próprios alunos e professores. Tal resultado vem ao encontro de Wagner, Oliveira e Caballo (2011), ao afirmarem que sujeitos que apresentam um bom repertório de $\mathrm{HS}$ podem ter mais facilidade de interação social e melhor capacidade de lidar com diferentes situações sociais nas quais estão envolvidos, ou seja, maior capacidade de desenvolver relacionamentos interpessoais satisfatórios por meio de habilidades de comunicação. 
A escola é um espaço não apenas de aprendizagem, mas de relações sociais. A qualidade das relações reflete no clima escolar, que é a percepção subjetiva de alunos, pais, professores e gestores, acerca das interações, regras, valores e formas de funcionamento da instituição. Assim, trabalhar com HS é uma forma de possibilitar que comportamentos assertivos sejam aprendidos. $\mathrm{O}$ presente trabalho corroborou os estudos de Caballo (2007), Wagner, Pereira e Oliveira (2014), Pureza, Rusch, Wagner e Oliveira (2012) e Wagner, Moraes, Oliveira e Oliveira (2017), nos quais houve a aplicação de THS com população universitária e foi comprovada a efetividade da intervenção no desenvolvimento das habilidades sociais.

\section{Considerações finais}

Constatou-se que foi alcançado o conteúdo das necessidades primordiais dos alunos, contribuindo com a promoção de saúde dos indivíduos envolvidos e também possibilitando o desenvolvimento das habilidades sociais e do adequado relacionamento em sala de aula, a fim de atingir os objetivos pedagógicos da instituição. Como refere Caballo (2007), quando o comportamento apresentado por um indivíduo trouxer dificuldades em seus relacionamentos interpessoais, é importante que alguma forma de intervenção seja proposta, através de estratégias específicas, buscando o desenvolvimento de suas habilidades sociais e aprimorando a sua convivência com os demais.

Algumas limitações foram encontradas no estudo. Estavam previstos mais encontros com os participantes, mas, como houve greve nas escolas estaduais, a continuidade do grupo ficou impossibilitada e foi necessário realizar o encerramento ao final de seis encontros.

A partir dos grupos, percebeu-se a necessidade do trabalho de desenvolvimento de habilidades sociais, não apenas com alunos, mas com todos os sujeitos que compõem a comunidade escolar (professores, equipe gestora e funcionários). Sugere-se a realização de grupos de THS com maior número de encontros, em grupos menores (de 5 a 8 participantes) e em diferentes escolas, com a realização de avaliação pré e pós intervenção das habilidades sociais, o que provavelmente trará dados que irão contribuir com os resultados aqui já encontrados.

\section{Referências}

Alonso, C., Gallego, D., \& Honey, P. (1994). Los estilos de aprendizaje. Procedimientos de diagnóstico y mejora. Bilbao: Mensajero.

Andrada, E. (2005). Novos paradigmas na prática do psicólogo escolar. Psicologia: Reflexão e Crítica, 18(2), 196-199.

Recuperado de http://www.scielo.br/pdf/\%0D/prc/v18n2/2 7470.pdf

Caballo, V. E. (1996). O treinamento em habilidades sociais. In V. E. Caballo (org.), Manual de técnicas de terapia e modificação do comportamento (pp. 3-42). São Paulo: Santos Livraria Editora. Caballo, V. (2003). Manual de Avaliação e Treinamento das Habilidades Sociais. São Paulo: Livraria Santos Editora.
Caballo, V. (2007). Manual de Técnicas de Terapia e Modificação do Comportamento. São Paulo, SP: Santos.

Caballo, V. (2012). Manual de Avaliação e Treinamento das Habilidades Sociais. Santos, SP: Santos Editora.

Caballo, V. E., Salazar, I. C., Irurtia, M. J., Arias, B., Hofmann, S. G. (2010a).

Measuring social anxiety in 11 countries: development and validation of the Social Anxiety Questionnaire for Adults. European Journal of Psychological Assessment, 26(2), 95-107. doi: 10.1027/1015-5759/a000014

Caballo, V. E., Salazar, I. C., Arias, B, Irurtia, M. J., Calderero, M. (2010b). Validación del "Cuestionario de Ansiedad Social para Adultos" (CASO-A30) em universitarios españoles: similitudes y diferencias entre 
carreras universitarias y comunidades autónomas. Psicología Conductual: Revista Internacional Clínica y de la Salud, 18(1), 5-34.

Cunha, J. A. (2001). Manual da versão em português das Escalas Beck. São Paulo: Casa do Psicólogo.

Del Barco, B. L., Castaño, E. F., Lázaro, S. M \& Gallego, D. I. (2015). Habilidades sociales en equipos de aprendizaje cooperativo en el contexto universitário. Psicología conductual, 23 (2), 191-214.

Del Prette, A. \& Del Prette, Z. A. P. (2009). Inventário de habilidades sociais para adolescentes (IHSA-Del-Prette): Manual de aplicação, apuração e interpretação. São Paulo: Casa do Psicólogo.

Del Prette, A., \& Del Prette, Z. A. P. (2010). Programa vivencial de habilidades sociais: Características sob a perspectiva da análise do comportamento. In M. R. Garcia, P. R. Abreu, E. N. P. de Cillo, P. B. Faleiros \& P. Piazzon (Orgs.), Sobre comportamento e cognição: Terapia comportamental e cognitiva (pp. 127-150). Santo André: ESETec.

Del Prette, A. \& Del Prette, Z. A. P. (2011). Habilidades Sociais: Intervenções efetivas em grupo. São Paulo, SP: Casa do Psicólogo.

Del Prette, A. \& Del Prette, Z. A. P. (2013). Programas eficaces de entrenamiento en habilidades sociales con base en vivenciales. Apuntes de Psicología, 31(1), 67-76. Recuperado de http://www.apuntesdepsicologia.es/index.p hp/revista/article/view/300/280

Del Prette, A. \& Del Prette, Z. A. P. (2017). Habilidades sociais de comunicação e feedback. In Z. Del Prette \& A. Del Prette, Habilidades Sociais e Competência Social (pp. 59-81). São Carlos: EdUFSCar.

Del Prette, Z. A. P. \& Del Prette, A. (1999). Psicologia das habilidades sociais: terapia e educação. Petrópolis: Vozes.

Del Prette, Z. A. P. \& Del Prette, A. (2001). Inventário de Habilidades Sociais (IHSDel-Prette): Manual de aplicação, apuração e interpretação. São Paulo: Casa do Psicólogo.
Del Prette, Z. A. P., \& Del Prette, A. (2005). Psicologia das habilidades sociais na infância: teoria e prática. Petrópolis, RJ: Vozes.

Del Prette, Z. A. P., \& Del Prette, A. (2009a). Avaliação de habilidades sociais: Bases conceituais, instrumentos e procedimentos. Em A. Del Prette \& Z. A. P. Del Prette (Orgs.), Psicologia das habilidades sociais: Diversidade teórica e suas implicações (pp. 187-229). Petrópolis, RJ: Vozes

Del Prette, Z. A. P. \& Del Prette, A. (2009b). Psicologia das Habilidades Sociais: Terapia, Educação e Trabalho. Rio de Janeiro, RJ: Petrópolis.

Del Prette, Z. A.P. \& Del Prette A. (2016). Inventário de Habilidades Sociais (IHSDel-Prette): Manual de aplicação, apuração e interpretação ( $1^{\mathrm{a}}$ reimpressão). São Paulo: Casa do Psicólogo.

Del Prette, Z. A. P., \& Del Prette, A. (2019). Instrumentos de avaliação das habilidades sociais no Brasil. In M. N. Baptista, M. Muniz, C. T. Reppold, C. H. S. S. Nunes, L. F. Carvalho, R. Primi, A. P. P. L. Pasquali. Compêndio de Avaliação Psicológica (pp. 376-396), Petrópolis: Vozes

Del Prette, Z. A. P., Falcone, E. M. O., \& Murta, S. G. (2013). Contribuições do campo das habilidades sociais para a compreensão, prevenção e tratamento dos transtornos de personalidade. In L. F. Carvalho, \& R. Primi (Orgs.), Perspectivas em psicologia dos transtornos da personalidade: Implicações teóricas e práticas (pp. 326-358). São Paulo: Casa do Psicólogo.

Del Prette, Z. A. P., Paiva, M., \& Del Prette, A. (2005). Contribuições do referencial das habilidades sociais para uma abordagem sistêmica na compreensão do processo de ensino-aprendizagem. Interações 5(2), 5772, Recuperado de http://pepsic.bvsalud.org/scielo.php?script= sci_arttext\&pid=S141329072005000200005

Deming, D. (2017). The growing importance of social skills in the labor market. The 
Quarterly Journal of Economics, 132(4), 1593-1640. doi: 10.1093/qje/qjx022

Dias, A. C. G., Patias, N. D., \& Abaid, J. L. W. (2013). Psicologia escolar e possibilidades na atuação do psicólogo: algumas reflexões. Psicologia Escolar e Educacional, 18(1), 105-111, 2014.

Recuperado de http://agricolawww.redalyc.org/articulo.oa? id=28233052 0011

Leme, V., Coimbra, S., Gato, J., Fontaine, A., \& Del Prette, Z. (2013). Confirmatory Factor Analysis of the Generalized SelfEfficacy Scale in Brazil and Portugal. The Spanish Journal of Psychology, 16, E93. doi: $10.1017 /$ sjp.2013.93

Leme, V. B. R., Fernandes, L. M., Jovarini, N. V., Achkar, A. M., \& Del Prette, Z. A. P. (2016). Social Skills Program for Adolescents in Vulnerable Social Contexts. Psico-USF, 21(3), 595-608. doi: 10.1590/1413-82712016210313

Lopes, D.C., Dascanio, D., Ferreira, B. C., Del Prette, Z.A. P., \& Del Prette, A. (2017). Treinamento de habilidades sociais: avaliação de um programa de desenvolvimento interpessoal profissional para universitários de ciências exatas. Interação em Psicologia, 21(01), 55-65. doi: $10.5380 / p s i . v 21 i 1.36210$

Maia, D., \& Lobo, B. (2013). O desenvolvimento da habilidade de solução de problemas interpessoais e a convivência na escola. Psicologia em Revista, 19(1), 1729. Recuperado de http://pepsic.bvsalud.org/scielo.php?script= sci_arttext\&pid=S1677$11682013000100003 \& \ln g=p t \& t \operatorname{lng}=p t$

Pureza, J. R., Rusch, S. G. S., Wagner, M., \& Oliveira, M. S. (2012). Treinamento de habilidades sociais em universitários: uma proposta de intervenção. Revista Brasileira de Terapias Cognitivas, 8(1), 2-9.

Recuperado de http://pepsic.bvsalud.org/scielo.php?script= sci_arttext\&pid=S180856872012000100002\&lng $=p t \& t \operatorname{lng}=p t$

Santos, D. C. O., Menezes, A. B. C., Borba, A., Ramos, C. C., \& Costa, T. D. (2017). Mapeamento de competências do psicólogo escolar. Psicologia Escolar e Educacional, 21(2), 225-234. doi: 10.1590/21753539201702121109

Soares, A., Mourão, L., Santos, A., \& Mello, T. (2016). Habilidades Sociais e Vivência Acadêmica de Estudantes Universitários. Interação em Psicologia, 19(2), 211-223. doi: 10.5380/psi.v19i2.31663

Squassoni, C., \& Matsukura, T. (2014). Adaptação transcultural da versão portuguesa do social support appraisals para o Brasil. Psicologia: Reflexão e Crítica, 27(1), 71-80. doi: 10.1590/S010279722014000100009

Terra, M. B., Barros, H. M. T,Stein, A. T,Figueira, I., Athayde, L. D, Tergolina, L. P,Rovani, J. S, Silveira, D. X. (2006). Internal consistency and factor structure of the Portuguese version of the Liebowitz Social Anxiety Scale among alcoholic patients. Revista Brasileira de Psiquiatria, 28 (4), 265-269.

Tosta, L., Silva, T., \& Scorsolini-Comin, F. (2016). O relato de experiência profissional e sua veiculação na ciência psicológica. Clínica \& Cultura, 2(1), 62-73. Recuperado de

https://seer.ufs.br/index.php/clinicaecultura/ article/view/6016/5994

Wagner, M. F., Oliveira, M., \& Caballo, V. (2011). Treinamento de Habilidades Sociais e sua aplicabilidade na prática clínica. In M. Oliveira \& I. Andretta (Orgs.), Manual prático de terapia cognitivocomportamental (pp. 537-552). São Paulo: Casa do Psicólogo.

Wagner, M. F., Pereira, A., \& Oliveira, M. (2014). Intervención sobre las dimensiones de la ansiedad social por medio de un programa de entrenamiento en habilidades sociales. Psicología Conductual, 22(3), 423. Recuperade de http://www.funveca.org/revista/pedidos/pro duct.php?id_product $=647$

Wagner, M. F., Moraes, J. F. D., Oliveira, A. A. W., \& Oliveira, M. S. (2017). Análise fatorial do Questionário de Ansiedade Social para Adultos. Arquivos Brasileiros de Psicologia, 69(1), 61-72. Recuperado de http://pepsic.bvsalud.org/scielo.php?script= 
sci_arttext\&pid=S1809-

$\underline{52672017000100006 \& \operatorname{lng}=p t \& t \operatorname{lng}=p t}$

\section{Dados sobre as autoras:}

- Jéssica Reusch Cruz: Psicóloga (IMED).

- Márcia Fortes Wagner: Psicóloga, Doutora em Psicologia (PUCRS), Docente nos cursos de Graduação e Mestrado em Psicologia na Faculdade Meridional (IMED).

- Naiana Dapieve Patias: Psicóloga, Especialista em Psicologia Escolar (FATO), Doutora em Psicologia (UFRGS), Docente dos cursos de graduação e mestrado em Psicologia na Faculdade Meridional (IMED). 